\title{
Body expressions of emotions: does animals have it?
}

\author{
Miguel Machado iD. Iran José Oliveira da Silva (iD
}

M Machado (Corresponding author) - IJO Silva

Ambience Research Group (NUPEA), Departament of

email: miguelmac89@gmail.com

Biosystems Engeneering, University of São Paulo (USP), Av.

Pádua Dias, 11, 13418-900, Piracicaba, São Paulo, Brazil.

Received: April 30, 2019 • Accepted: June 25, 2019 • Published Online: August 29, 2019

\begin{abstract}
The expression of emotions in animals is a source of information not very explored by researches. It is necessary to know what emotions animals experience and how these emotions are expressed to the point that we can identify them. Within this approach, the use of techniques to measure body changes in animals according to the type of emotion experienced is one of the following paths. The ear and tail positioning was described as body areas subject to changes caused by emotions in animals. However, the position of the ears and tail may vary between species when it comes to the emotional state and therefore, it is not possible to establish a pattern. It is necessary to evaluate each species individually and the results cannot be transmitted from one species to another. In addition, animals demonstrate different facial expressions associated with pain. Changes in facial expression in animals may also be related to emotions.
\end{abstract}

Keywords: cattle, ears, facial expression, tail

\section{Introduction}

The science of animal welfare is concerned with promoting improvements in living conditions, housing, slaughter, health, sanitation, management, nutrition, expression of natural behaviors, among many other factors. Much has been studied on how to improve these conditions and reduce the negative effects of intensive animal farming on individual animals. Today, it is believed that the well-being of an animal raised for food production also involves the promotion of positive emotional experiences and states (Forkman et al 2007; Proctor 2012; Fraser et al 2013).

The expression of emotions in animals is a source of information little explored by research, and can provide important data that can function as indicators of well-being, and the relationship of animals with their environment, caretakers, etc. Such indicators can be incorporated into automated technological systems, such as softwares, considering the development of applied technologies in agriculture to evaluate the state of well-being in animais (Paul et al 2005; Meunier et al 2017; Van Hertem et al 2017; Norton and Berckmans, 2017; Halachmi et al 2018).

For this, it is necessary to know what emotions cattle experience and how these emotions are expressed, to the point that we can identify them. The welfare of dairy cows in any type of milk production system is affected positively or negatively by multiple factors such as: interactions with other cows, with humans, with the management system, facilities design, nutritional management, climate and other environmental conditions.

The use of automated milking systems, for example, allows cows to have greater control over their activities and provides greater opportunity for interaction with the environment, but results in a milking experience with social isolation, since the milking "is individualized, which increases stress responses in dairy cows (Jacobs and Siegford 2012).

The same reaction can be observed in systems of individually calf rearing, when compared to collective system. In addition, calves when are separated from their mother have poor social skills, difficulties in dealing with novelties, impaired learning ability and probably intensified negative emotions (Costa et al 2016).

Due to the subjective nature of the emotions, many believe that it is not possible to measure or understand the emotional life of animals. If these emotions could be identified quickly and easily, much discomfort could be avoided. For this, it is necessary to develop indicators of visible and believable emotional states (Proctor et al 2015).

Within this approach, the use of techniques to measure body changes in animals according to the type of emotion experienced is one of the following paths. This fact may facilitate the understanding of the behavior or sensation animals are submitted to, and different situations that may produce some kind of stimulus (+ or -) and, consequently, their reflexes.

Some authors (Sandem et al 2002; Sandem et al 2004; Sandem and Braastad 2005; Sandem et al 2006; Reefmann et al 2009a; Reefmann et al 2009b; Boissy et al 2011; Reimert et 
al 2013; Proctor and Carder 2014; Gleerup et al 2015; Proctor and Carder 2015; Lambert and Carder 2017; Reimert et al 2017; Barros et al 2017; Bellegarde et al 2017; Stellato et al 2017; Oliveira and Keeling, 2018; Tamioso et al 2018; Paul and Mendl 2018; Amelia et al 2018; Flint et al 2018; Lambert and Carder 2019) used the measurement of body changes for the identification and correlation with the emotions expressed as a function of the stimuli received.

\section{Ear postures as body expression}

Indicators need to be practical, reliable and easily observable. In order to investigate whether ear positions were useful to characterize the emotional states of free sheep in the pasture, Reefman et al (2009) submitted 19 female sheep to probable situations in the induction of negative, intermediate and positive emotional states. The authors concluded that negative emotional states are characterized by a high number of changes in the position of ears, while positive emotional states resulted in a high proportion of passive ears.

In preliminary studies, Boissy et al (2011) sought to identify the link between ear posture and emotional states in sheep by means of three experiments. In experiment 1 the animals were surprised by a fast or slow moving object. In experiment 2 , sheep trained to receive a large feed reward (pellet 50g) received a small reward (pellet 10g). In experiment 3, the authors used an air blower to scare the animals. The authors found that negative emotional experiences in sheep resulted in the "ears back" position when the situation was uncontrollable and "ears standing" when the situation was controllable, whereas positive emotions resulted in flat ears. The ear positions considered in the study by Boissy et al (2011) can be observed in Figure 1.

Position of the ears in relation to the frontal plane of the head

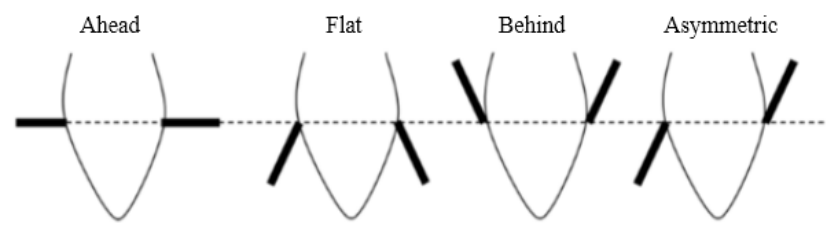

Auricles orientation

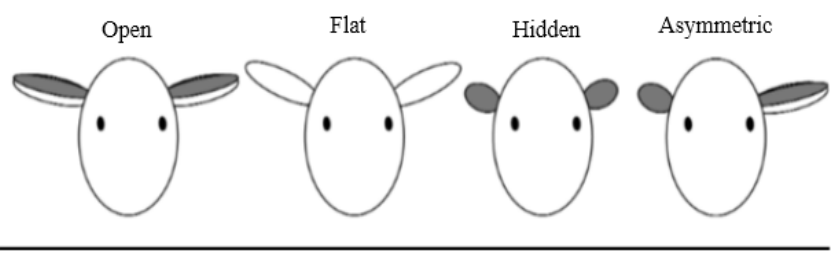

Figure 1 Position of ears collected from sheep according to two criteria: position of the ears in relation to the frontal plane of the head (above) and orientation of the auricles (below). Adapted from Boissy et al (2011).
The ear position in ewes was also studied by Tamioso et al (2018). The authors evaluated the different ear positions (up, horizontal, backward and asymmetrical) in sheep selected for high and low reactivity, against the presence of a known human and the stroking received by a known human. All behavioral indicators showed that animals had a more pleasurable experience when they were stroked compared to the mere presence of a known human. In these animals the horizontal ears were more observed, what suggested a relation with a relaxing effect in the most reactive animals.

The position of ears in goats that visualized images of other goats receiving a negative stimulus (ice block leaning on the udder) and a positive one (caressing the neck) were studied by Bellegarde et al (2017), who showed that the animals had more attention to negative images, with higher proportion of ears forward, compared to the responses from positive images.

Simulating the stimulation of body areas that are frequently licked by other cows in an attempt to identify whether ear postures can be used to measure the positive emotional state of dairy cows, Proctor et al (2014) and Lambert and Carder (2019) concluded that this observation provides a quick, noninvasive and low-cost measure. Thus, the position of ears is an indication, as a practical tool, to assess the emotional state of dairy cows.

Behavioral observations are spontaneous and immediate, while other measures, such as physiological ones, require time and equipment to be measured. Using the observation of ear positions as a measure of emotional state requires training, but can be reliable and consistent. In addition, because emotions are short-lived and fast responses, it is possible that ear positions can provide an immediate indicator of the emotional state of the animals (Proctor et al 2014).

The body posture of seventy-two lactating cows were evaluated by Oliveira and Keeling (2018) while the animals performed different activities in a loose house system. One of the variables studied was the position of ears while the cows were stroked, fed and queuing. The authors found positive interactions between the ears positions studied (Figure 2) and the activities of the animals, so that at the moments when the animals were stroked and fed (positive stimuli) the ears backwards were the most observed positions.

The relationship between ear positioning and emotions in dogs were studied by Stellato et al (2017) and Flint et al (2018) who concluded that the ear position in these animals is strongly associated with the manifestation of negative emotions, caused by stimuli from the environment.

The position of the ears may vary between species when it comes to the emotional state and therefore it is not possible to establish a pattern. It is necessary that each species is evaluated individually and the results are not transmitted from one species to another. 


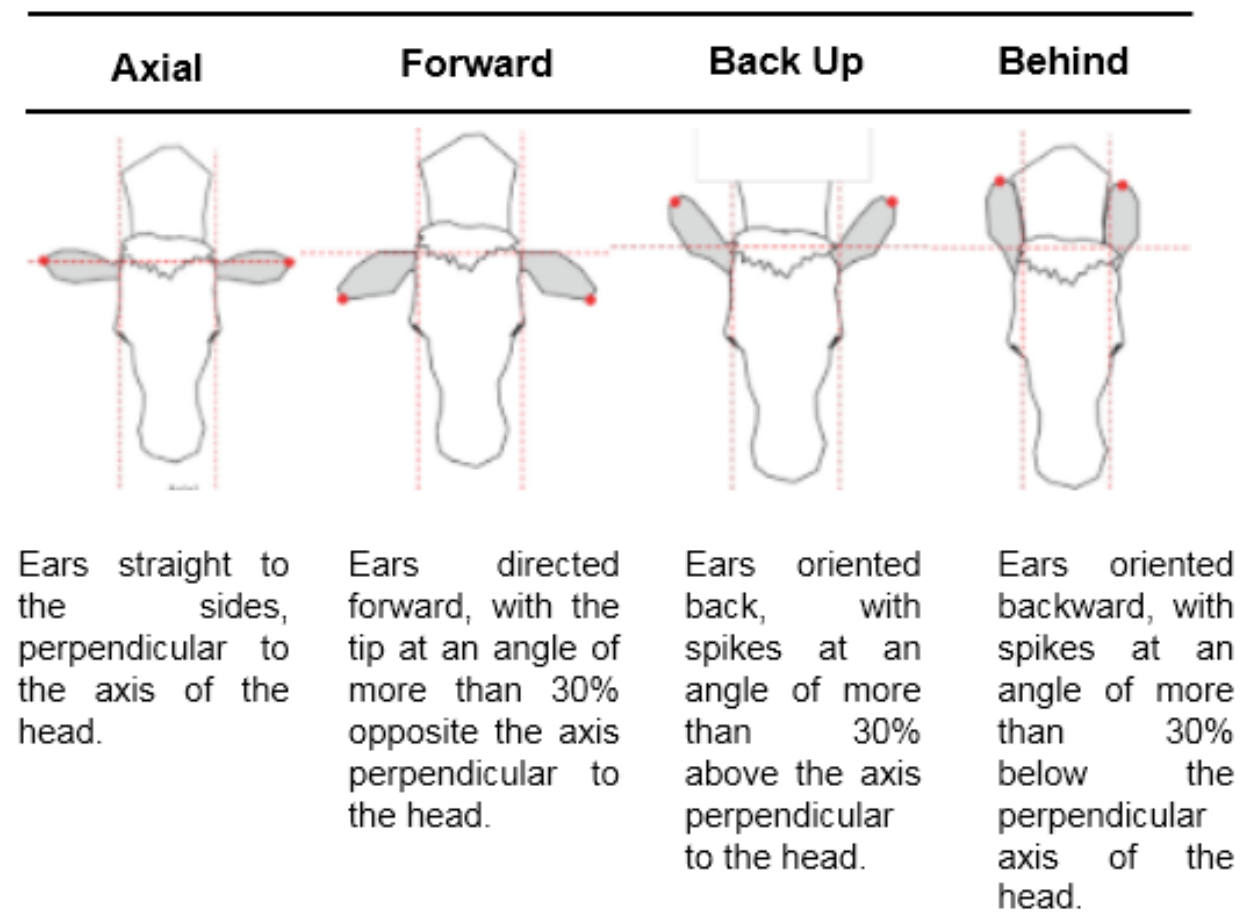

Figure 2 Diagrammatic representation of observed ear positions while animals were stroked, fed and queuing. Adapted from Oliveira and Keeling (2018).

\section{Can tail position also be an indicator of emotion expression?}

Some researches (Wemelsfelder et al 2001; Quaranta et al 2007; Reefmann et al 2009a; All e Terms 2013; Briefer et al 2015; Stellato et al 2017; Oliveira and Keeling 2018; Futro et al 2018; Larsen et al 2018; Wallgren et al 2019) were published with the objective of relating tail movement, as a body area, with the expression of emotion facing different situations, in several species.

The study of the positioning and the movement of the tail is notorious when it comes to dogs, since several authors have reported the relation of the tail positioning with the emotions in these animals (Quaranta et al 2007; Artelle et al 2011; Siniscalchi et al 2013; Stellato et al 2017; Flint et al 2018).

Quaranta et al (2007) studied the asymmetry in the control of tail movements in dogs and amplitudes to the left and right movements, associated with the type of visual stimulus received. When the dogs saw their owners, they exhibited a movement with remarkable bias to the right and with great amplitude. A similar response was observed when the dogs visualized an unknown human, but with a smaller range of motion.

In the visualization of a cat, the dogs showed few tail movements, but still with a bias to the right. When they saw an unknown dog, they presented a bias of tail movement to the left. The authors concluded that there is a fundamental asymmetry in the control of emotions-related functions, and this asymmetry is related to the activated cerebral area/hemisphere, also called cerebral lateralization (Quaranta et al 2007).

According to Stellato et al (2017), dogs in an emotional situation of fear exhibit lower tail movements and tend to position them between the hind limbs, as a sign of expression of this emotion.

The behavior of fear in puppies of dogs was studied by Flint et al (2018), in which they demonstrated that this species, when submitted to a negative emotional state, exhibits a large tail lowering, with absence of movement, followed by the positioning of the tail between the hind limbs, until it touches the final portion of the abdomen.

Regarding farm animals, Oliveira and Keeling (2018) studied tail movements in dairy cows during three activities: stroking, feeding and queuing. The authors found that the relaxed tail was the most frequent position in all situations. In addition, the arched tail to the side was observed during stroking, and rapid movements against the body during feeding. Thus, the study assumed that tail movements in cows may be associated with positive valenced emotions (Figure 3).

Briefer et al (2015) identified that sheep spent more time with the tail arched upwards in positive situations when compared to negative situations. Tail positions were also suggested as indicators of emotions in sheep and pigs (Reefmann et al 2009; Boissy et al 2011; Futro et al 2018; 
Larsen et al 2018; Wallgren et al 2019) and were considered noninvasive indicators of excitement and emotional valence.

Reefmann et al (2009a) found that the upward tail position in sheep occurs only during an intense negative emotional state. However, Grant (2004) has previously shown that calves and lambs raise their tails while they suck, and qualitative observations have shown that tame sheep raise their tails while being stroked by humans.

Reimert et al (2013), Futro et al (2018) e Larsen et al (2018) suggest that tail movements, in general, may be a good behavioral indicator for positive emotions in pigs. The authors found that the tail movement and the large number of changes in their position were observed more frequently during positive and rewarding events as compared to negative events. According to the authors, the tail posture in pigs (up and down) seems to be an early indication of cannibalism, an important problem that leads to consequences to animal welfare.

Therefore, it is important to consider the behavioral responses of positioning and tail movement of different animal species as exclusive, since each species has a pattern of tail movement and this may be related to opposite emotional states. In addition, they may vary with age. Therefore, it is necessary to investigate in a specific way the tail positioning behaviors facing different situations for each animal species.

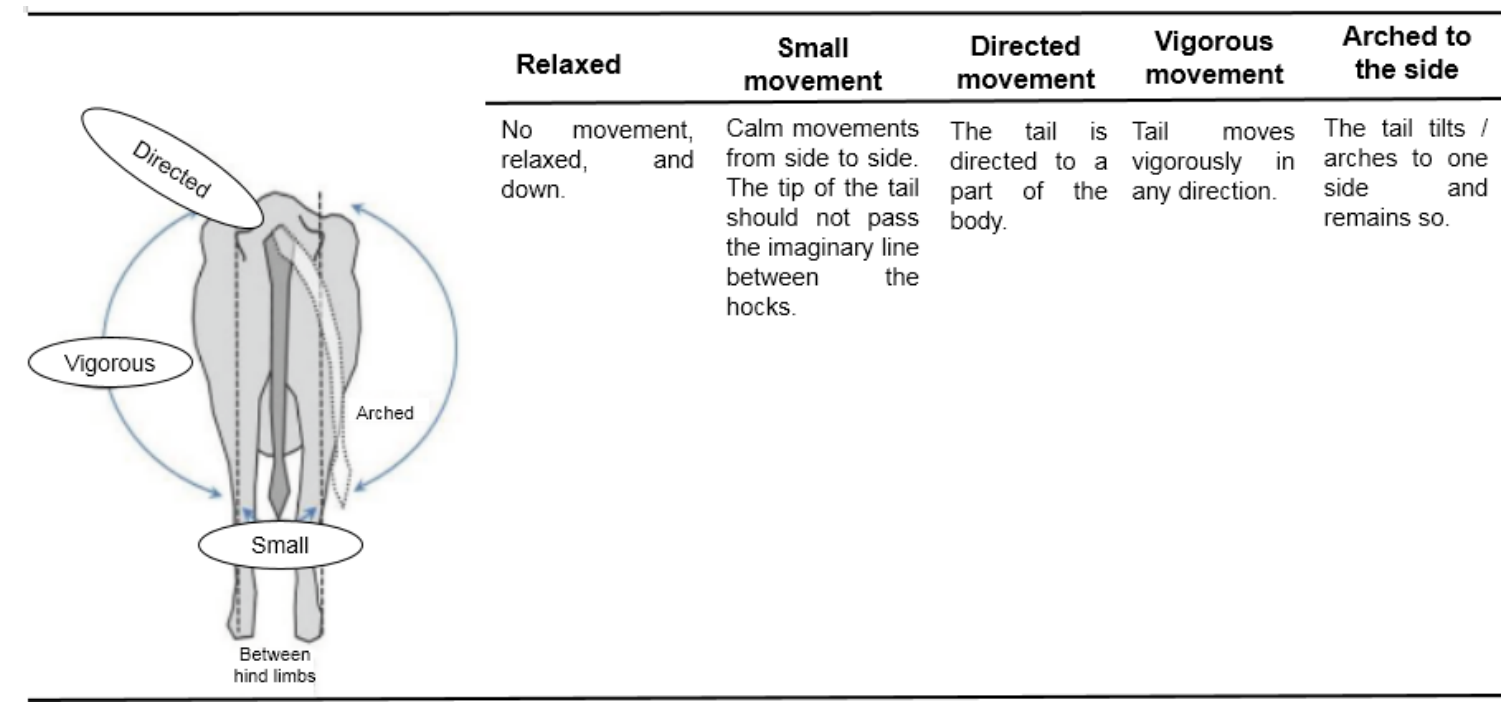

Figure 3 Diagrammatic representation of tail positions observed while animals were stroked, fed and milked for milking. Adapted from Oliveira and Keeling (2018).

\section{Facial expression and emotions in animals}

In humans, facial expression has been extensively studied through changes in facial features. The facial expression analysis system in humans (FACS) is based on the description of muscular contractions (units of action) on the face. The combination of these units forms the expression of an emotion in a person (Boissy et al 2011).

Expression of emotions is mainly determined by brain structures such as the limbic system, which is conserved and shared among the higher phyla of vertebrates. In every kind of social animal, the display of emotion is a source of information. Therefore, signs of emotion represent, besides emotional responses, a form of communication between animals that have good visual acuity (Tate et al 2006).

Ungulate animals, such as sheep and cattle, use facial features to display emotional information. However, according to Tate et al (2006) these views would be limited to emotions of negative valence. However, the authors state that a possible absence of facial expression during negative situations plays an important role in social communication. Facial traces related to negative emotions in ungulates include exposure of eye white and dilated nostrils.

Studies involving the facial expression of animals, mostly, are related to the evaluation of pain intensity.

Some authors (Langford et al 2010; Keating et al 2012; Dalla Costa et al 2014; Gleerup et al 2015; Müller 2015; McLennan et al 2016; Barros et al 2017; Lu et al 2017; Amelia et al 2018; Kopaczka et al 2018) studied the expression of pain in cattle, sheep, rats and horses, and demonstrated that facial signs of pain are present.

Gleerup et al (2015) studied facial expression of pain in cattle and identified changes in facial action units that may be related to changes from bad emotions. Besides the ears, discussed here in another item, dilated nostrils, tense eyes and eyebrow tension were the expressions found (Figure 4).

Pain characteristics compromised five areas in the face of bovines:

- Eyes: wide-eyed and tense; 
- Eyebrow: Muscle tension in the area just above the eyes;

- Jaw: tension in the muscles of the side of the head;

- Muzzle: muscular tension above the muzzle and dilated nostrils;

- Mouth: increased tension in the lips.

Dalla Costa et al (2014) developed and validated an equine pain assessment score based on facial expressions (Figure 5). This method can represent a viable and reliable way, using the natural human instinct to pay attention to the head and face to identify expressions of pain and emotions in other people or animals.
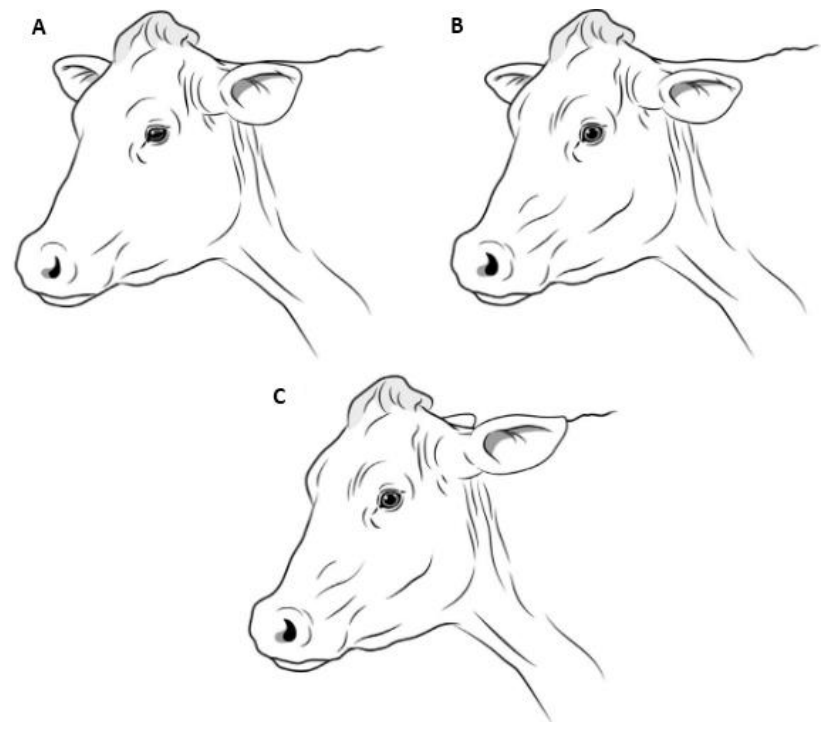

Figure 4 Illustration of changes in facial expression of cows. (A) relaxed animal. (B and C) animal suffering pain. Adapted from Gleerup et al (2015).

When developing a standard scale/score of facial expression associated with pain in adult sheep, McLennan et al (2016) found changes in facial units that may also be modified by positive or negative valenced emotions (Figure $6)$.

Amelia et al (2018) showed that harbor seals (Phoca vitulina) react to painful stimuli caused by microchip marking, by means of quantitative changes in facial action units, such as opening and closing of the eyes and closing the nostrils, as described for other species (Figure 7).

Tate et al (2006) revealed great facial recognition ability among sheep, similar to that found in humans. Bellegarde et al (2017) studied the facial reaction of goats submitted to co-specific images exhibiting positive and negative emotional states, and concluded that the animals had different reactions to the photographs, so that they appeared to be more attentive to the photos of conspecific in negative situations.

In these studies, eyes seem to have been the most important feature for recognition.
Sandem et al (2004) published a study seeking to find facial expression of emotions through the white area exposed in the eyes as a reflex of fear when cattle were subjected to an unexpected negative stimulus. The unexpected stimulus was a rapidly opened umbrella near the animal's head. The authors found a $13 \%$ increase in eye white during the negative stimulus, and concluded that this measure may indicate fear in cattle and also that the opening of the umbrella next to the animal was an effective stimulus causing fear.

The percentage of eye white area (ocular sclera) in the eye of cattle has been measured as an indicator of emotional state in some studies (Sandem et al 2006; Proctor and Carder 2015; Lambert and Carder 2017; Gómez et al 2018; Jimenez et al 2019) and was associated with a strong emotional response in dairy cows (Sandem and Braastad 2005). The percentage of the visible white area increases when the upper eyelid is lifted.

In their study, Sandem and Braastad (2005) investigated the percentage of white area in the eye as a dynamic indicator of frustration and satisfaction in dairy cows. The negative stimulus was the separation of the calf of four days of age, and the positive stimulus was the return of the calf after six hours. The percentage of eye white increased significantly after the calf was removed, with a peak at 4 minutes. When the calf was placed back with the cow, the white area in the eye decreased over the first four minutes.

Exposure of eye whites reflects a strong emotional response, either negative or positive (Sandem et al 2006). Even if observations of behavior patterns can be used to separate positive and negative situations, such behaviors appear scattered over time and can be easily lost.

Proctor and Carder (2015) studied the simulation of "alogrooming" (positive social interaction between cows, represented by the act of one animal licking the other) through the caress and evaluated the percentage of eye whites in adult cows during three moments: before, during and after stroking. In this study, there was a significant difference in the percentage of white area in the eye, between the three periods, and this percentage was lower during the stroking time.

These results support the hypothesis that the percentage of eye white decreases in response to positive stimuli, such as stroking.

The existence of positive emotions is essential to ensure that animals have a good life within intensive farming systems. Like us humans, positive experiences are important elements in animals life (Proctor and Carder 2015).

By studying the heart rate and percentage of eye white in lactating cows versus three different positive stimuli (standard feed, concentrated feed and lumps of wood), Lambert and Carder (2017) found increased percentage of eye white during the offering of new food (concentrated food and lumps of wood). 


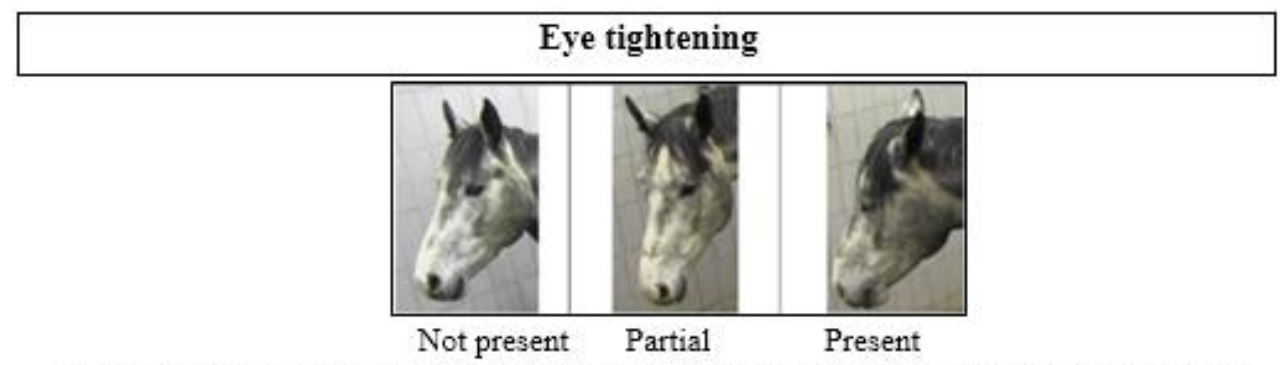

The eyelids are partially or totally closed. Any movement of the eyelid that reduces the area of the eye by more than $50 \%$ should be considered as present.

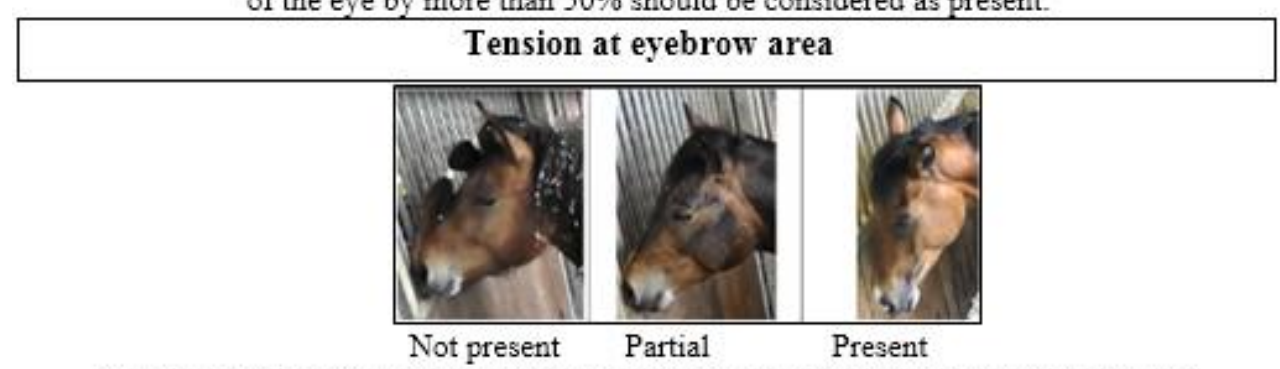

The contraction of the muscles above the eyes causes increased visibility of the bone surfaces.
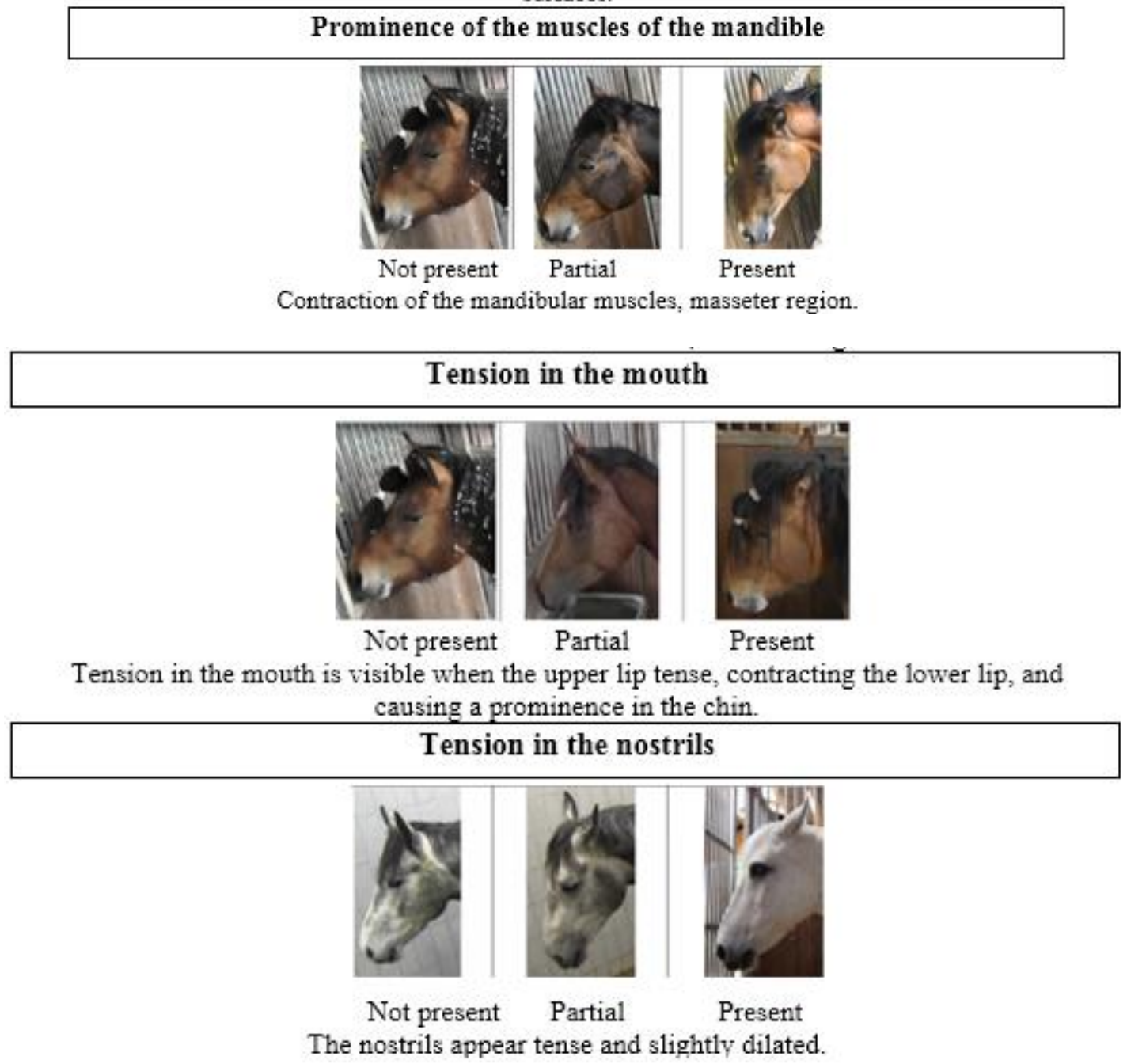

Figure 5 Equine pain assessment score (HGS), based on facial action units. Adapted from Dalla Costa et al (2014). 


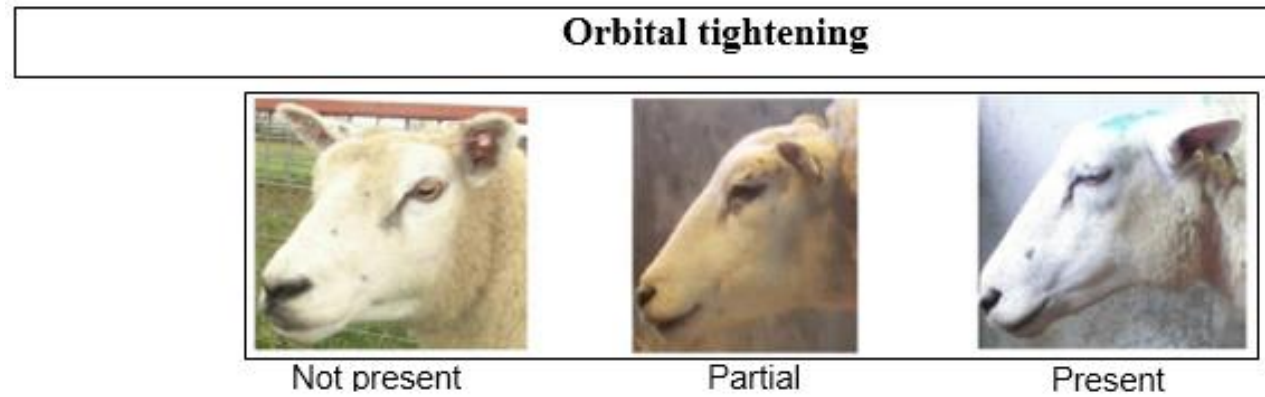

There is closing of the eyelids and contraction of the ocular opening.

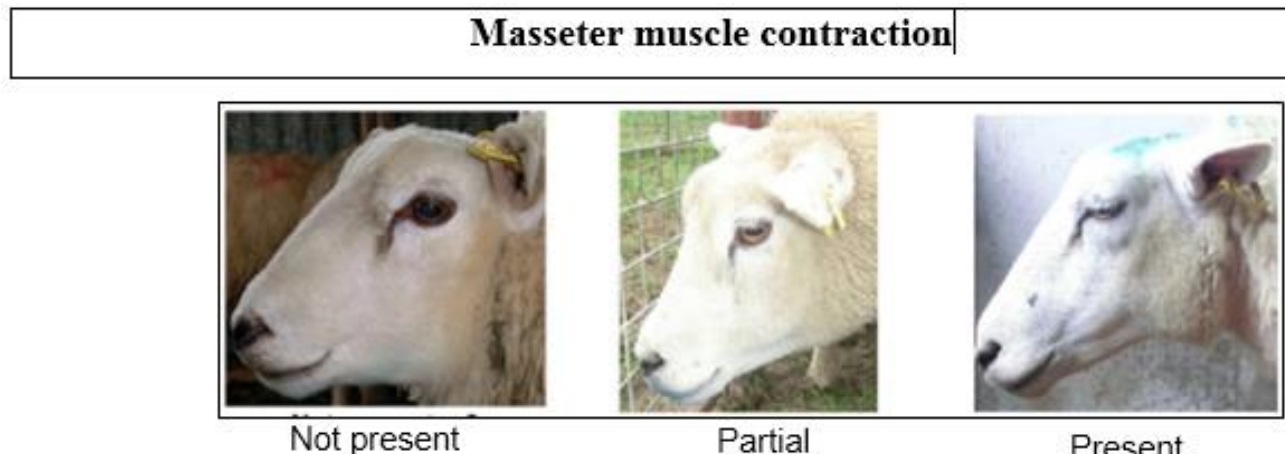

There is a more convex shape in the area of the masseter and zygomatic arch.

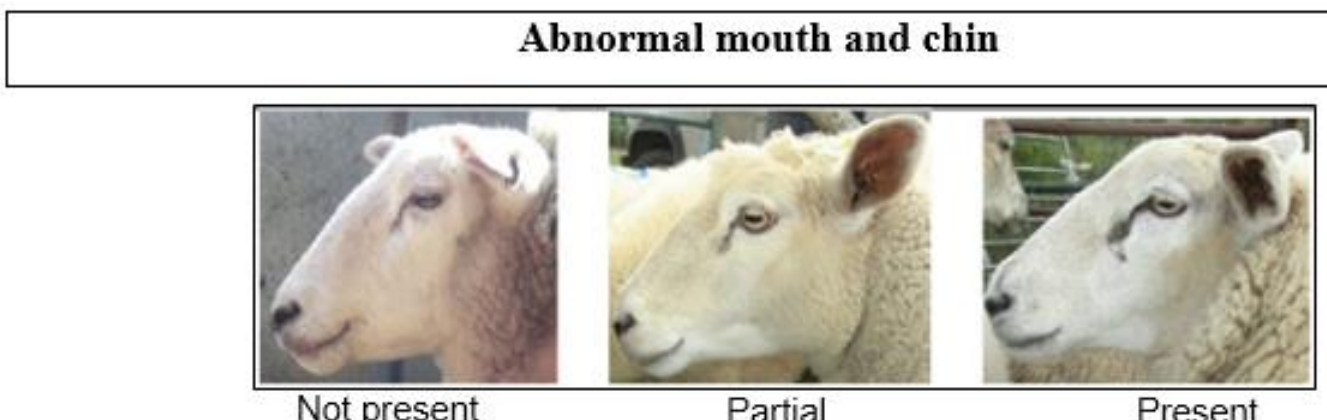

The lower lip is pulled back, and the chin appears concave. The line of the chin and jaw is aligned. The line from the lips to the comer of the mouth is straightened.

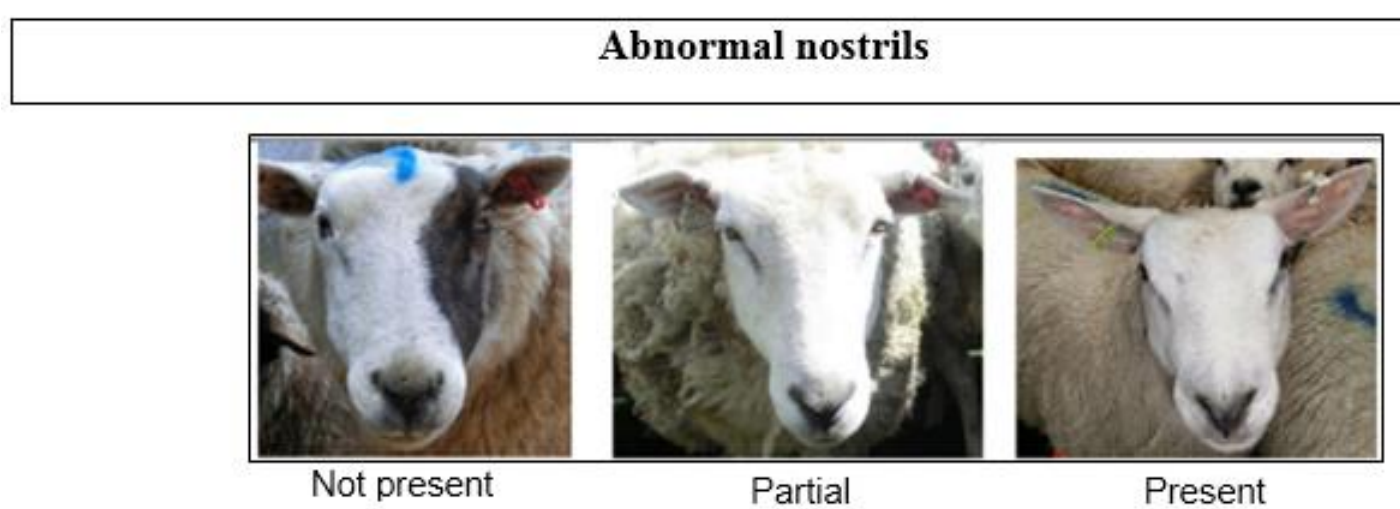

A pronounced " $\mathrm{v}$ " shape between the lips and the opening of the nostrils is present.

Figure 6 Facial expression scale to pain in sheep. Adapted from McLennan et al (2016). 


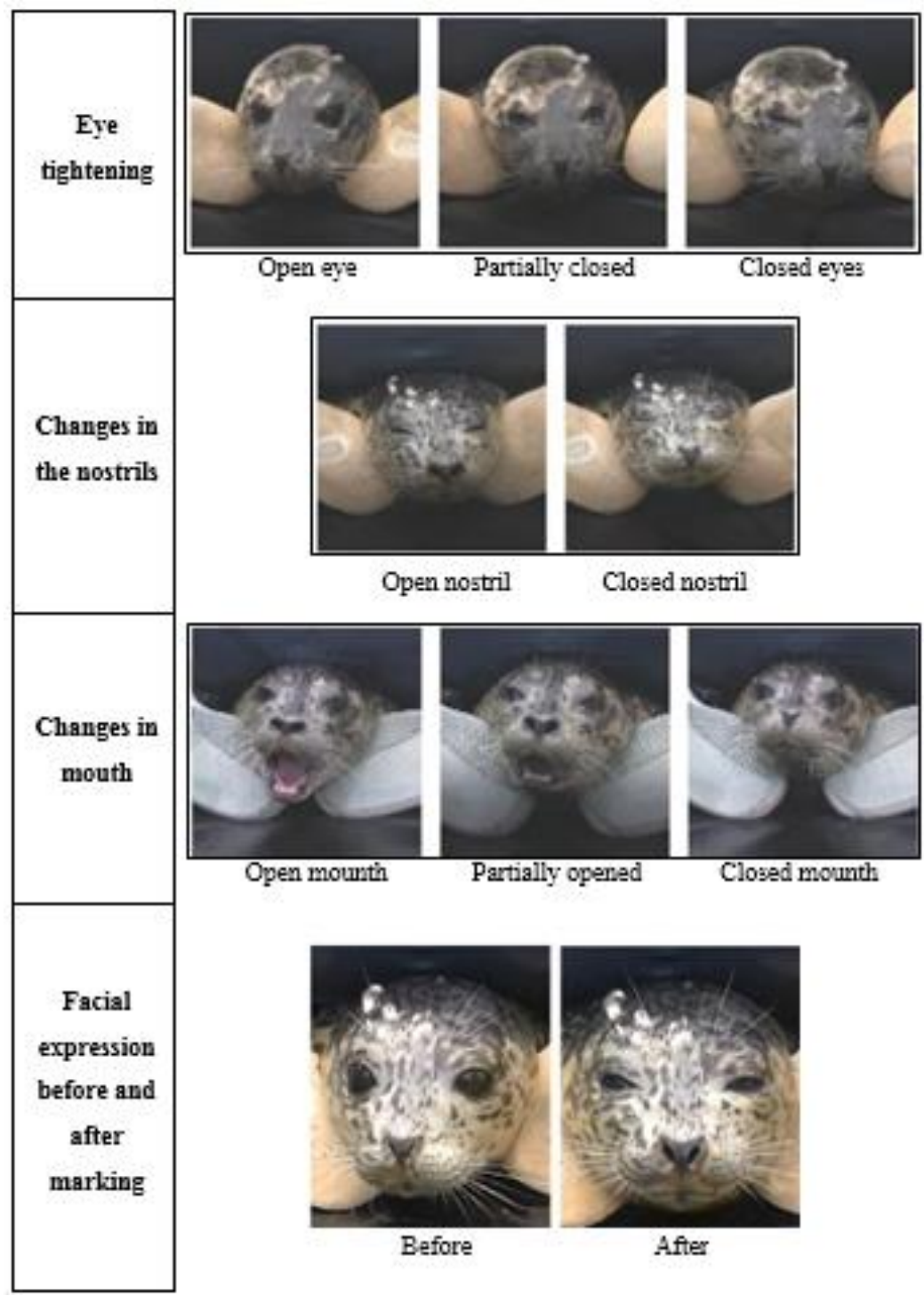

Figure 7 Seal (Phoca vitulina) facial action units subjected to microchip marking. Adapted from Amelia et al (2018).

The development of direct measures that are easy to use and applicable in different contexts are essential to understand whether animals are free of negative emotions and constantly experiencing positive states (Lambert and Carder 2017).

People notice the animal's face to try to interpret emotions (Lakestani et al 2014). In particular, in the eyes, when trying to seek or guess emotional states, such as joy, sadness or fear. This attention to facial changes seems to be important for humans to assess and understand emotions in other species, and can help us to develop methods and ways to properly identify them (Amelia et al 2018).

In addition, there is much interest from companies that are already using visual computing to evaluate facial expressions of animals, thanks to the development of software based on artificial intelligence and algorithms, to make facial recognition of animals from images captured by cameras (Kumar et al 2016a; Kumar et al 2016b; Gu et al 2017; Kumar et al 2017; Kumar et al 2018a; Kumar et al 2018b; Li et al 2019).

\section{Final considerations}

There is a relationship between tail and ear postures and the emotional state of animals. The use of these body areas can provide a useful tool, easily accessible and with no cost to assess the emotional state of farm animals, but knowledge about animal behaviour is necessary. However, the development of studies in this area will contribute to the progress and calibration of artificial intelligence software, through computer vision, capable of identifying emotions in animals from changes in body variables such as ears and tail. 


\section{Acknowledgements}

To the Coordination of Improvement of Higher Education - Brazil (CAPES) - Financing Code 001 - for the support to carry out the project.

\section{References}

All PM, Terms J (2013) The tail movements of ungulates, canids and felids with particular reference to their causation and function as displays. BRILL Stable. 56:69-115. Acessed on December 30, 2018

Amelia A, Macrae M, Makowska IJ, Macrae AM, Makowska IJ, Fraser D (2018) Initial evaluation of facial expressions and behaviours of harbour seal pups (Phoca vitulina) in response to tagging and microchipping. Applied Animal Behaviour Science. doi:S0168159118302235

Artelle KA, Dumouli, LK, Reimchen TE (2011) Behavioural responses of dogs to asymmetrical tail wagging of a robotic dog replica. Laterality. doi:10.1080/13576500903386700

Barros J, Maria R, Pires L, Ambrósio LA, Oliveira A De, Trevisan G (2017) Expressão facial , vocalização e posturas anômalas em bovinos submetidos à eletroejaculação convencional. PubVet 11:1074-1187.

Bellegarde LGA, Haskell MJ, Duvaux-ponter C, Weiss A, Boissy A, Erhard HW (2017) Face-based perception of emotions in dairy goats. Applied Animal Behaviour Science. doi:10.1016/j.applanim.2017.03.014

Boissy A, Aubert A, Désiré L, Greiveldinger L, Delval E, Veissier I (2011) Cognitive sciences to relate ear postures to emotions in sheep. Animal Welfare 20:47-56.

Briefer E F, Tettamanti F, Mcelligott A G (2015) Emotions in goats : mapping physiological , behavioural and vocal profiles. Animal Behaviour. doi:10.1016/j.anbehav.2014.11.002

Costa J H C, von Keyserlingk M A G, Weary D M (2016) Invited review: Effects of group housing of dairy calves on behavior, cognition, performance, and health. Journal of Dairy Science. doi:10.3168/JDS.2015-10144

Dalla Costa E, Minero M, Lebelt D, Stucke D, Canali E, Leach M C (2014) Development of the Horse Grimace Scale (HGS) as a pain assessment tool in horses undergoing routine castration. PLoS One. doi:10.1371/journal.pone.0092281

Flint H E, Coe J B, Serpell J A, Pearl D L, Niel L (2018) Identification of fear behaviors shown by puppies in response to nonsocial stimuli. Journal of Veterinary Behaviour. doi:10.1016/j.jveb.2018.07.012

Forkman B, Boissy A, Meunier-Salaün M C, Canali E, Jones R B (2007) A critical review of fear tests used on cattle, pigs, sheep, poultry and horses. Physiology \& Behaviour. doi:10.1016/j.physbeh.2007.03.016

Fraser D, Duncan I J H, Edwards S A, Grandin T, Gregory N G, Guyonnet V, Hemsworth P H, Huertas S M, Huzzey J M, Mellor D J, Mench J A, Špinka M, Whay H R (2013) General Principles for the welfare of animals in production systems: The underlying science and its application. Veterinary Journal. doi:10.1016/j.tvj1.2013.06.028

Futro A, Barclay D, Zhu Q, Baxter E M, D'Eath R B, Jack M, Talbot D (2018) Automatic early warning of tail biting in pigs: 3D cameras can detect lowered tail posture before an outbreak. PLoS One. doi:10.1371/journal.pone.0194524
Gleerup K B, Andersen P H, Munksgaard L, Forkman B (2015) Pain evaluation in dairy cattle. Applied Animal Behaviour Science. doi:10.1016/j.applanim.2015.08.023

Gómez Y, Bieler R, Hankele A K, Zähner M, Savary P, Hillmann E (2018) Evaluation of visible eye white and maximum eye temperature as non-invasive indicators of stress in dairy cows. Applied Animal Behaviour Science. doi:10.1016/j.applanim.2017.10.001

Grant C (2004) Behavioural responses of lambs to common painful husbandry procedures. Applied Animal Behaviour Science. doi:10.1016/j.applanim.2004.01.011

Gu Jingqiu, Wang Zhihai, GAO Ronghua (2017) Cow behavior recognition based on image analysis and activities. International Journal of Agricultural and Biological Engineering. doi:10.3965/j.ijabe.20171003.3080

Halachmi I, Guarino M, Bewley J, Pastell M (2018) Smart Animal Agriculture: Application of Real-Time Sensors to Improve Animal Well-Being and Production. Annual Reviews Animal Bioscience. doi:10.1146/annurev-animal-020518-114851

Jacobs J A, Siegford J M (2012) Invited review: The impact of automatic milking systems on dairy cow management, behavior, health, and welfare. Journal of Dairy Science. doi:10.3168/jds.20114943

Jimenez R E, Adcock S J J, Tucker C B (2019) Acute pain responses in dairy calves undergoing cornual nerve blocks with or without topical anesthetic. Journal of Dairy Science. doi:10.3168/jds.201815445

Keating S C J, Thomas A A, Flecknell P A, Leach M C (2012) Evaluation of EMLA Cream for Preventing Pain during Tattooing of Rabbits: Changes in Physiological, Behavioural and Facial Expression Responses. PLoS One doi:10.1371/journal.pone.0044437

Kopaczka M, Ernst L, Heckelmann J, Schorn C, Tolba R, Merhof D (2018) Automatic Key Frame Extraction from Videos for Efficient Mouse Pain Scoring. 2018 5th Int. Conf. Signal Process. Integr. Networks, SPIN. doi:10.1109/SPIN.2018.8474046

Kumar S, Pandey A, Sai Ram Satwik K, Kumar S, Singh S K, Singh A K, Mohan A (2018a) Deep learning framework for recognition of cattle using muzzle point image pattern. Measurement. doi:10.1016/j.measurement.2017.10.064

Kumar S, Singh S K, Abidi A I, Datta D, Sangaiah A K (2018b) Group Sparse Representation Approach for Recognition of Cattle on Muzzle Point Images. International Journal of Parallel Programming. doi:10.1007/s10766-017-0550-x

Kumar S, Singh S K, Datta T, Gupta HP (2016a) A Fast Cattle Recognition System using Smart devices. Proceedings of the 24th ACM international conference on Multimedia. doi: $10.1145 / 2964284.2973829$

Kumar S, Singh S K, Singh R S, Singh A K, Tiwari S (2017) Realtime recognition of cattle using animal biometrics. Journal of RealTime Image Processing. doi:10.1007/s11554-016-0645-4

Kumar S, Tiwari S, Singh S K (2016b) Face Recognition of Cattle: Can it be Done? Proceedings of the National Academy of Sciences, India Section A: Physical Sciences. doi:10.1007/s40010-016-0264-2

Lakestani N N, Donaldson M L, Waran N (2014) Interpretation of Dog Behavior by Children and Young Adults. Anthrozoos. doi:10.2752/175303714X13837396326413

Lambert (Proctor) H S, Carder G (2017) Looking into the eyes of a 
cow: Can eye whites be used as a measure of emotional state? Applied Animal Behaviour doi:10.1016/j.applanim.2016.11.005

Lambert H, Carder G (2019) Positive and negative emotions in dairy cows: Can ear postures be used as a measure? Behaviour Processes. doi:10.1016/j.beproc.2018.12.007

Langford D J, Bailey A L, Chanda M L, Clarke S E, Drummond T E, Echols S, Glick S, Ingrao J, Klassen-Ross T, Lacroix-Fralish M L, Matsumiya L, Sorge R E, Sotocinal S G, Tabaka J M, Wong D, Van Den Maagdenberg A M J M, Ferrari M D, Craig K D, Mogil J S (2010) Coding of facial expressions of pain in the laboratory mouse. Nature Methods. doi:10.1038/nmeth.1455

Li Z, Shen S, Ge C, Li X (2019) Cow Individual Identification Based on Convolutional Neural Network. Proceedings of the 2018 International Conference on Algorithms, Computing and Artificial Intelligence. doi:10.1145/3302425.3302460

Lu Y, Mahmoud M, Robinson P (2017) Estimating sheep pain level using facial action unit detection. Biometrics. doi:10.1109/FG.2017.56

McLennan K M, Rebelo C J B, Corke M J, Holmes M A, Leach M C, Constantino-Casas F (2016) Development of a facial expression scale using footrot and mastitis as models of pain in sheep. Applied Animal Behaviour Science. doi:10.1016/j.applanim.2016.01.007

Meunier B, Pradel P, Sloth K H, Cirié C, Delval E, Mialon M M, Veissier I (2017) Image analysis to refine measurements of dairy cow behaviour from a real-time location system. Biosystems Engineering doi:10.1016/j.biosystemseng.2017.08.019

Müller B R (2015) Dor em bovinos na marcação a ferro quente: expressão facial, outros indicadores comportamentais e fisiológicos e a percepção dos produtores. Dissertation, Universidade Federal do Paraná.

Norton T, Berckmans D (2017) Developing precision livestock farming tools for precision dairy farming. Animal Frontiers. doi:10.2527/af.2017.0104

Oliveira D De, Keeling L J (2018) Routine activities and emotion in the life of dairy cows : Integrating body language into an affective state framework. Plos One. doi:10.17605/OSF.IO/9JVR6

Paul E S, Harding E J, Mendl M (2005) Measuring emotional processes in animals: The utility of a cognitive approach. Neuroscience \& Biobehavioral Reviews. Rev. doi:10.1016/j.neubiorev.2005.01.002

Paul E S, Mendl M T (2018) Animal emotion: Descriptive and prescriptive definitions and their implications for a comparative perspective. Applied Animal Behaviour Science. doi:10.1016/j.applanim.2018.01.008

Proctor H (2012) Animal sentience: Where are we and where are we heading? Animals. doi:10.3390/ani2040628

Proctor H S, Carder G (2015) Measuring positive emotions in cows: Do visible eye whites tell us anything? Physiology \& Behaviour. doi:10.1016/j.physbeh.2015.04.011

Proctor H S, Carder G (2014) Can ear postures reliably measure the positive emotional state of cows? Applied Animal Behaviour Science. doi:10.1016/j.applanim.2014.09.015

Quaranta A, Siniscalchi M, Vallortigara G (2007) Asymmetric tailwagging responses by dogs to different emotive stimuli. Current Biology. doi:10.1016/j.cub.2007.02.008

Reefmann N, Bütikofer Kaszàs F, Wechsler B, Gygax L (2009a) Ear and tail postures as indicators of emotional valence in sheep. Applied
Animal Behaviour Science. doi:10.1016/j.applanim.2009.02.013

Reefmann N, Wechsler B, Gygax L (2009b) Behavioural and physiological assessment of positive and negative emotion in sheep. Animal Behaviour. doi:10.1016/j.anbehav.2009.06.015

Reimert I, Bolhuis J E, Kemp B, Rodenburg TB (2013) Indicators of positive and negative emotions and emotional contagion in pigs. Physiology \& Behaviour. doi:10.1016/j.physbeh.2012.11.002

Reimert I, Fong S, Rodenburg T B, Bolhuis J E (2017) Emotional states and emotional contagion in pigs after exposure to a positive and negative treatment. Applied Animal Behaviour Science. doi:10.1016/j.applanim.2017.03.009

Sandem A I, Braastad B O (2005) Effects of cow-calf separation on visible eye white and behaviour in dairy cows - A brief report. Applied Animal Behaviour Science. doi:10.1016/j.applanim.2005.04.011

Sandem A I, Braastad B O, Bakken M (2006) Behaviour and percentage eye-white in cows waiting to be fed concentrate-A brief report. Applied Animal Behaviour Science. doi:10.1016/j.applanim.2005.08.003

Sandem A I, Braastad B O, Bøe K E (2002) Eye white may indicate emotional state on a frustration-contentedness axis in dairy cows. Applied Animal Behaviour Science. doi:10.1016/S01681591(02)00029-1

Sandem A I, Janczak A M, Braastad B O (2004) A short note on effects of exposure to a novel stimulus (umbrella) on behaviour and percentage of eye-white in cows. Applied Animal Behaviour Science. doi:10.1016/j.applanim.2004.06.011

Siniscalch M, Lusito R, Vallortigara G, Quaranta A (2013) Seeing left- or right-asymmetric tail wagging produces different emotional responses in dogs. Current Biology. doi:10.1016/j.cub.2013.09.027

Stellato A C, Flint H E, Widowski T M, Serpell J A, Niel L (2017) Assessment of fear-related behaviours displayed by companion dogs (Canis familiaris) in response to social and non-social stimuli. Applied Animal Behaviour Science. doi:10.1016/j.applanim.2016.12.007

Tamioso P R, Maiolino Molento C F, Boivin X, Chandèze H, Andanson S, Delval É, Hazard D, da Silva G P, Taconeli C A, Boissy A (2018) Inducing positive emotions: Behavioural and cardiac responses to human and brushing in ewes selected for high vs low social reactivity. Applied Animal Behaviour Science. doi:10.1016/j.applanim.2018.08.001

Tate A J, Fischer H, Leigh A E, Kendrick K M (2006) Behavioural and neurophysiological evidence for face identity and face emotion processing in animals. Philosophical Transactions of the Royal Society. doi:10.1098/rstb.2006.1937

Van Hertem T, Rooijakkers L, Berckmans D, Peña Fernández A, Norton T, Berckmans D, Vranken E (2017) Appropriate data visualisation is key to Precision Livestock Farming acceptance. Computers and Electronics in Agriculture. doi:10.1016/j.compag.2017.04.003

Wallgren T, Larsen A, Gunnarsson S (2019) Tail Posture as an Indicator of Tail Biting in Undocked Finishing Pigs. Animals. doi:10.3390/ani9010018

Wemelsfelder F, Hunter T E A, Mendl M T, Lawrence A B (2001) Assessing the "whole animal": A free choice profiling approach. Animal Behaviour. doi:10.1006/anbe.2001.1741 